BMJ Open Sport \& Exercise Medicine

\title{
Short-term recovery of physical activity and knee function after an acute knee injury
}

\author{
Sanne Fomin, ${ }^{1}$ Håkan Gauffin, ${ }^{2}$ Joanna Kvist (i) ${ }^{1,3}$
}

To cite: Fomin S, Gauffin H, Kvist J. Short-term recovery of physical activity and knee function after an acute knee injury. BMJ Open Sport \& Exercise Medicine 2020;6:e000950. doi:10.1136/ bmjsem-2020-000950

- Additional material is published online only. To view, please visit the journal online (http://dx.doi.org/10.1136/ bmjsem-2020-000950).

Accepted 17 December 2020

Check for updates

(c) Author(s) (or their employer(s)) 2020. Re-use permitted under CC BY-NC. No commercial re-use. See rights and permissions. Published by BMJ.

'Unit of Physioptherapy, Department of Health, Medicine and Caring Science, Linköping University, Linköping, Sweden ${ }^{2}$ Orthopaedics. Department of Biomedical and Clinical Sciences, Linköping University, Linköping, Sweden

${ }^{3}$ Center for Medical Image Science and Visualization (CMIV) Department of Health, Medicine and Caring Sciences, Linköping University, Linköping, Sweden

Correspondence to Professor Joanna Kvist; joanna.kvist@liu.se

\section{ABSTRACT}

Objectives To describe self-reported knee function, participation in physical activity and the number of knee surgeries at 3 and 6 months following acute knee injury. Methods Prospective cohort study. Participants, aged 15-40 years with an acute knee injury sustained no more than 6 weeks prior to inclusion, were recruited. There were 279 participants with ACL injury and 101 participants with other acute knee injuries included. Follow-up questionnaires were sent at 3 and 6 months after injury. Demographic information, activity participation, International Knee Documentation Committee subjective knee form (IKDC-SKF) and the Single Assessment Numeric Evaluation (SANE) score were collected. Additional knee injuries were obtained from self-report and medical charts. Results The IKDC-SKF, SANE and physical activity participation were reduced at 3-month and 6-month follow-up. The number of participants who achieved health-promoting physical activity levels was reduced by $50 \%$ at 6 -month follow-up compared with before injury. Seventeen per cent of participants with ACL injury and $41 \%$ of participants with other acute knee injuries had returned to their preinjury physical activity at 6 months. Participants with ACL injury reported worse knee function, lower physical activity participation and had more surgeries (128 surgeries, including 109 ACLreconstructions) compared with participants with other acute knee injuries (six surgeries).

Conclusion Acute knee injuries, including ACL injuries, affected self-reported knee function and physical activity participation for at least 6 months after index injury. More research is needed to understand how best to help people with acute knee injuries return to physical activity and achieve satisfactory knee function.

\section{INTRODUCTION}

In Sweden, knee injuries account for approximately $8 \%$ of all acute musculoskeletal injuries presenting to hospital emergency departments every year. About one-third of these injuries occurred during sports. ${ }^{1}$ Although many acute injuries occur during physical activity participation, the healthrelated benefits of being physically active outweigh the risks of injury.

Physical activity is a collective term for all activities that at moderate intensity lead to
What are the new findings?

- Acute knee injuries, including ACL injuries, affected self-reported knee function and physical activity participation at a minimum 6 months after index injury.

- Most patients with acute knee injury did not achieve full recovery in the first 6 months after injury.

How might it impact on clinical practice in the near future?

Clinicians should give more attention to patients with acute knee injury in order to help them return to their preinjury physical activity, and achieve satisfactory knee function.

faster breathing, increased heart rate and feeling warmer. Adults are recommended to participate in at least $150 \mathrm{~min} /$ week of moderate intensity physical activity per week, to realise health benefits. Physical activity can be a walk, run or going to the gym but also includes organised and competitive sports. ${ }^{2}$ Basketball, football, handball and floorball are the sports with most participants in Sweden, and where knee injuries are most common. ${ }^{13}$ ACL injuries are the most investigated acute knee injury, but other ligament injuries, meniscal injuries, cartilage injuries or patellar dislocation are common acute knee injuries ${ }^{14}$ that affect knee-specific function. 56

Physical activity is decreased following any type of acute knee injury and many patients do not return to preinjury level of physical activity. ${ }^{7-14}$ Sports are many young people's primary physical activity ${ }^{15}$ and especially team sports have a positive effect on social and psychological health. ${ }^{16}$ All types of physical activity are important to benefit health, improve and maintain quality of life, and for reducing the risk of many diseases including knee osteoarthritis. $^{2} 17$ Most studies investigate how return to physical activity is affected 
after an ACL injury or reconstruction. The effect of other acute knee injuries on participation in physical activity is less studied. Previous observations suggest that level of physical activity participation following knee injury may differ according to the type of injury. ${ }^{50-14}$ The aim of the present study was to describe self-reported knee function, participation in physical activity and the number of knee surgeries at 3 and 6 months following acute knee injury.

\section{METHODS}

\section{Setting}

This study is a part of the NACOX study that is a prospective, multicentre cohort study. ${ }^{18}$ Patients or the public were not involved in the design, or conduct, or reporting, or dissemination plans of our research. Participants were consecutively recruited over approximately 20 months, from six different sites in Sweden. Participants provided informed consent to participate.

\section{Participants}

People seeking medical care, between October 2016 and October 2018, for an acute knee injury sustained no more than 6 weeks prior to presentation, and aged between 15 and 40 years at time of injury, were eligible. Some clinics included all participants with knee injuries and other clinics only included participants with ACL injury. Participants were excluded if they met any of following criteria: previous ACL injury/reconstruction to the same knee, fractures that required separate treatment, inability to understand written and spoken Swedish language, cognitive impairments, other illness or injury that impaired function (eg, fibromyalgia, rheumatic diseases and other diagnoses associated with chronic pain).

\section{Procedure}

Participants were recruited between October 2016 and October 2018. Participants received a clinical diagnosis from an orthopaedic surgeon and MRI when required to confirm the diagnosis and were treated according to usual care. For ACL injuries, participants usually undergo rehabilitation before a decision for ACL reconstruction (ACLR). Other surgeries, for example, meniscectomies, are performed when needed according to patients' symptoms (for more details, see the NACOX protocol $^{18}$ ). In the NACOX study, questionnaires are sent to the participants via short message at smartphone or email at various time points after injury. For the current analysis, data collected using the baseline questionnaire, and 3-month and 6-month follow-up questionnaires were analysed. In addition, medical charts with 6 months follow-up after the injury were reviewed.

\section{Outcomes}

Demographic and baseline characteristics including age, sex, body mass index, occupation, preinjury activity and level of participation, medical and injury history were collected. Specific questions were asked about recovery expectations ('when do you think your knee will be recovered to the same level as before the injury?', answer options: within 1 week, within 1 month, within 6 months, within 1 year, more than 1 year, the knee will never recover) and recovery of knee function, ('how do you rate your knee function compared with before the injury', graded in a six-point scale from 'fully recovered' to 'much worse').

For self-reported knee function, participants completed the Swedish version of the International Knee Documentation Committee subjective knee form (IKDC-SKF) and the Single Assessment Numeric Evaluation (SANE-score). ${ }^{19}$ The IKDC-SKF is a knee-specific self-reported outcome measure for symptoms, function and participation in sports. The IKDC-SKF has good measurement properties. ${ }^{20}{ }^{21}$ Possible scores range from 0 to 100; a higher score indicates superior self-reported knee function. Minimal clinical important difference early after ACLR is 14 points. ${ }^{20}$ Muller $e t a l^{22}$ defined 75.9 points and over were acceptable symptoms for patients who had undergone ACLR. The SANE is a 1-question measure where participants answer the question 'If I had to give my knee a grade from 1 to 100 , with 100 being the best, I would give my knee a ...' The SANE-score has good validity and is positively correlated with IKDC-SKF score. ${ }^{19} 23$

Self-reported frequency of participation in vigorous physical activity was collected, according to the recommendations from Swedish National Board of Welfare, with a separate question, "how much time did you spend last week on exercising at a level that makes you short winded, for example, running, fitness class or ball games'. ${ }^{24}$ Participants reported the type of physical activity they participated in (eg, football, strength training) and the level of participation during the previous week. Participation in up to three activities could be recorded at every questionnaire. The most strenuous activity was analysed.

Activity level was classified according to Tegner Activity Scale ${ }^{25}$ and modified IKDC activity level. ${ }^{2627}$ In the Tegner Activity Scale, sports activities and work are graded on an 11-level scale, according to functional demands on the knee. Level 0 is no participation in physical activity due to knee problems; level $\mathrm{X}$ is participation in elite football. In the modified IKDC, activity is classified in four levels: level I is pivoting and contact sports, level II is pivoting non-contact sports and III is neither pivoting nor contact sport. Participants who were not participating in physical activity, or who are completing rehabilitation were classified in level IV.

Information about any knee surgery during the follow-up period was collected by a direct question to the participants and reviewing medical charts.

\section{Data analysis}

For the current analyses, participants were grouped according to injury in two main groups, that is, ACLinjury and other knee injuries. Specific diagnoses are reported in online supplemental file. Participants with 
two or more knee injuries were grouped based on the most serious injury.

Injury groups are described with descriptive statistics. Missing data and loss to follow-up is reported under results and in tables.

Comparisons between groups were made with $\chi^{2}$ tests or Mann-Whitney $\mathrm{U}$ tests, and within groups with repeated analysis of variance (ANOVA) or Friedman with post-hoc tests, as appropriate.

\section{RESULT}

A total of 279 participants with ACL injury and 101 participants with other acute knee injuries answered the baseline questionnaire. Twelve participants (4\%) with ACL injury had a clinical diagnosis (no MRI) and 11 of them had later ACLR. Nine participants (9\%) with other knee injuries had clinical diagnosis (two medial collateral ligament (MCL) injuries, one meniscus injury (had meniscectomy 6 weeks after the index injury) and six with other knee injuries (three had no MRI due to medical reasons, ie, pregnancy, obesity and claustrophobia)). Forty-three per cent of the participants with ACL injuries had at least one concomitant injury (online supplemental file, table 1). Subgroup analyses revealed no significant differences in IKDC-SKF at 6 months between participants with and without concomitant injuries.

There were $219(78 \%)$ participants with ACL injury and $52(51 \%)$ participants with other acute knee injury who completed the questionnaire at 6 months follow-up (figure 1, online supplemental file).

\section{Demographics}

The most common activity at time of injury was football. The majority of participants were physically active at a 'recreational' or 'competitive' level before injury. Almost every participant (94\%) reported 'return to preinjury physical activity' was a rehabilitation goal (table 1).

\section{Self-reported knee function and knee problems}

Participants reported deteriorated knee function at all follow-up times, where $70 \%$ of the participants with ACL injury and $47 \%$ with other knee injuries reported IKDC-SKF score below the threshold of 75.9 defining patient acceptable state ${ }^{22}$ (table 2). The IKDC-SKF and SANE scores increased significantly from baseline to 3 and 6 months after injury. Fewer participants with ACL injury reported their knee function fully recovered at both 3 months and 6 months follow-up, compared with participants with other knee injuries $(p<0.001)$. At 6 months follow-up, $3 \%$ of participants with ACL injury compared with $23 \%$ of participants with other knee injuries reported their knee function was fully recovered.

\section{Return to and participation in physical activity}

Sixty-nine per cent of participants with ACL injury and $62 \%$ of participants with other knee injuries were physically active $>120 \mathrm{~min} /$ week before their knee injury. At 6-month follow-up, the number of participants who
Table 1 Baseline demographics

\begin{tabular}{|c|c|c|}
\hline Variable & $\begin{array}{l}\text { ACL injuries } \\
(n=279)\end{array}$ & $\begin{array}{l}\text { Other knee } \\
\text { injuries } \\
(n=101)\end{array}$ \\
\hline Age, mean (range) (years) & $25(15-40)$ & $25(15-40)$ \\
\hline Male/female, n (\%) & $136 / 143(49 / 51)$ & $56 / 45(55 / 45)$ \\
\hline $\mathrm{BMI}>25, \mathrm{n}(\%)$ & $79(29)^{4}$ & $33(34)^{4}$ \\
\hline \multicolumn{3}{|l|}{ Occupation, n (\%) } \\
\hline Student & $121(44)$ & $38(39)$ \\
\hline Employed & $147(53)$ & $57(58)$ \\
\hline Other & $8(3)^{3}$ & $3(3)^{3}$ \\
\hline \multicolumn{3}{|l|}{ Activity at injury, n (\%) } \\
\hline Football (soccer) & $110(39)$ & $36(36)$ \\
\hline Floorball & $34(12)$ & $5(5)$ \\
\hline Skiing & $55(20)$ & $14(14)$ \\
\hline Handball & $17(6)$ & $2(2)$ \\
\hline Basketball & $6(2)$ & $0(0)$ \\
\hline Sports on ice $†$ & $2(1)$ & $9(9)$ \\
\hline Spare time & $8(3)$ & $11(11)$ \\
\hline Other sports & $49(18)^{2}$ & $33(33)^{3}$ \\
\hline \multicolumn{3}{|l|}{ Physical activity level, n (\%) } \\
\hline Elite & $62(23)$ & $11(13)$ \\
\hline Competitive & $100(37)$ & $33(38)$ \\
\hline Recreational & $91(34)$ & $29(33)$ \\
\hline Other & $17(1)$ & $14(16)$ \\
\hline $\begin{array}{l}\text { Goal to return to preinjury } \\
\text { physical activity, } \mathrm{n}(\%)\end{array}$ & $257(93)$ & $87(94)$ \\
\hline \multicolumn{3}{|c|}{ Recovery expectation $\neq, \mathrm{n}(\%)$} \\
\hline$<6$ months & $136(50)$ & $81(86)$ \\
\hline$>6$ months & $120(44)$ & $9(10)$ \\
\hline Will never recover & $18(7)^{5}$ & $3(4)^{7 *}$ \\
\hline
\end{tabular}

Superscript number indicates number of participants with missing data.

*Significantly different to $A C L$ injury group $(p<0.05)$. †lce-hockey and bandy.

‡Question for recovery expectation: 'when do you think your knee will be recovered to the same level as before the injury?'.

$\mathrm{BMI}$, body mass index.

participated in $>120$ min physical activity per week was $27 \%$ and $35 \%$, respectively (no statistical difference between groups). Before injury, there was no difference between the groups in weekly participation in physical activity or type of physical activity. Activity level (Tegner Activity Scale and IKDC level) was decreased at 3 and 6 months after injury in both groups $(\mathrm{p}<0.001)$. Participants with ACL injury had a significantly lower Tegner Activity Scale score $(p=0.022)$ and IKDC level of activity $(p<0.001)$ at 3-month and 6-month follow-up compared with participants with other knee injuries (table 3 ).

At 6-month follow-up, $17 \%$ of participants with ACL injury and $41 \%$ of participants with other acute knee injuries had returned to their preinjury physical activity.

Problems related to the knee injury (currently completing rehabilitation, poor knee function or fear for 

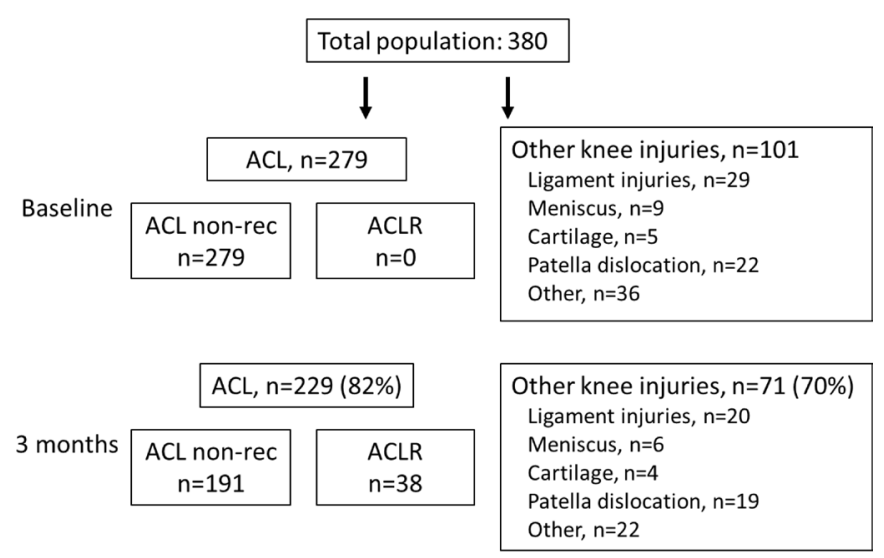

\begin{tabular}{|c|c|c|c|}
\hline \multirow[b]{2}{*}{6 months } & \multicolumn{2}{|c|}{$\mathrm{ACL}, \mathrm{n}=219(78 \%)$} & Other knee injuries, $n=52(51 \%)$ \\
\hline & $\begin{array}{c}\text { ACL non-rec } \\
n=125\end{array}$ & $\begin{array}{l}\mathrm{ACLR} \\
\mathrm{n}=94\end{array}$ & $\begin{array}{l}\text { Vleniscus, } \mathrm{n}=6 \\
\text { Cartilage, } \mathrm{n}=2 \\
\text { Patella dislocation, } \mathrm{n}=13\end{array}$ \\
\hline
\end{tabular}

Figure 1 Flowchart of participants, type of injury and number of participants at baseline, 3-month and 6-month follow-up. ACLR, ACL reconstruction.

new injury/not trusting the knee) was the reason for not returning to preinjury physical activity in $92 \%$ of participants with ACL injury and $83 \%$ of participants with other knee injuries (table 3 ).

\section{Surgery}

Of the 279 participants with ACL injury, 109 participants (39\%) had ACLR within the first 6 months after primary injury (mean 3.3, SD 1.5 months after injury) and 19 $(7 \%)$ had other knee surgeries. Six participants with other acute injuries $(6 \%)$, had knee surgery within the first 6 months after the primary injury (table 4, figure 2).

\section{DISCUSSION}

Self-reported knee function and physical activity participation was reduced at 3-month and 6-month follow-up after acute knee injury, and only one-third of participants were physically active at health-promoting levels (>120 $\mathrm{min} /$ week $^{2}$ ) 6 months after acute knee injury. Participants with ACL injury reported worse knee function and lower physical activity participation compared with participants with other acute knee injuries.

\section{Self-reported knee function}

Participants with ACL injury rated their knee function worse than participants with other acute knee injuries. However, our results suggest that other acute knee injuries also affect knee function. Fewer participants with ACL injury achieved full recovery within 6 months from the injury, but participants with other knee injuries were also frequently affected. Fewer than one in every four participants with other acute knee injuries were fully recovered at 6 months follow-up. McGuine et a $\tilde{e}$ reported similar results in female athletes, where IKDC-SKF score was reduced for a period of 3-12 months after acute knee injury. Knee function depended on type of knee injury, and even participants with injuries that were considered less serious were almost as affected as participants with ACL injury. Straume-Næsheim et $a l^{28}$ showed that patients with recurrent lateral patella dislocation were affected similarly to patients with ACL injury. However, patella dislocations were not treated in the same serious and effective way as ACL injuries, and patients had to wait longer for treatment. There is a strong focus on research of treatment and rehabilitation after ACL injury, and there are guidelines about how to manage ACL injury. ${ }^{29}$ Less is known about knee function and physical activity participation after other acute knee injuries. Although, our results suggest other acute knee injuries may have a similar impact to ACL injury.

Low self-reported knee function may be a reflection of our participants' high demands on knee function due to high activity level before their knee injury. Nearly three out of four participants were active in contact or pivoting sports before injury, and participation time, type and level of physical activity before the injury did not differ between the injury groups (ACL and other knee injuries). Both injury groups had reduced activity levels at 3-month and 6-month follow-up, and participants had switched to less knee demanding physical activity (eg, from football and floorball to cycling, walking, running and strength training). Although the goal of the majority

Table 2 Self-reported knee function at baseline, 3-month and 6-month follow-up

\begin{tabular}{|c|c|c|c|c|c|c|}
\hline & \multicolumn{2}{|c|}{ Baseline } & \multicolumn{2}{|c|}{3 months } & \multicolumn{2}{|c|}{6 months } \\
\hline & ACL $(n=279)$ & Other $(n=101)$ & $A C L(n=229)$ & Other $(n=71)$ & ACL $(n=219)$ & Other $(n=52)$ \\
\hline IKDC-SKF, mean (SD) & $43(15)^{49}$ & $51(17)^{30 *}$ & $55(17)^{29}$ & $66(19)^{2 *}$ & $63(19)^{68}$ & $74(18)^{3 *}$ \\
\hline SANE, mean (SD) & $39(21)^{9}$ & $47(20)^{5 \star}$ & $62(20)^{7}$ & $73(22)^{7 \star}$ & $66(21)^{9}$ & $76(24)^{5 *}$ \\
\hline \multicolumn{7}{|c|}{ Knee function recovery, $\mathrm{n}(\%)$} \\
\hline Fully recovered & & & $1(1)$ & $8(11)$ & $5(3)$ & $12(23)$ \\
\hline Large recovery & & & $117(54)$ & $47(67)$ & $103(60)$ & $31(60)$ \\
\hline Small/no recovery & & & $92(43)^{13}$ & $14(20)^{1 \star}$ & $58(34)^{49}$ & $9(17)^{*}$ \\
\hline
\end{tabular}

Superscript number indicates number of participants with missing data. Missing values at IKDC-SKF: at 3 months, 22 of the 29 patients in the ACLgroup had ACL-reconstruction within 3 months from injury and at 6 months, 65 of 68 patients had ACL-reconstruction within 6 months. *Significant different to ACL-group $(p<0.05)$.

IKDC-SKF, International Knee Documentation Committee subjective knee form; SANE, Single Assessment Numeric Evaluation. 
Open access

Table 3 Physical activity (PA) participation before and 3 and 6 months after the knee injury

\begin{tabular}{|c|c|c|c|c|c|c|}
\hline & \multicolumn{2}{|c|}{ Before injury } & \multicolumn{2}{|c|}{3 months } & \multicolumn{2}{|c|}{6 months } \\
\hline & $\operatorname{ACL}(n=279)$ & Other $(n=101)$ & ACL $(n=229)$ & Other $(n=71)$ & ACL $(n=219)$ & Other $(n=52)$ \\
\hline \multicolumn{7}{|c|}{ Weekly participation in PA at moderate intensity } \\
\hline 0 min, $\mathrm{n}(\%)$ & $1(0)$ & $3(3)$ & $48(22)$ & $8(11)$ & $46(22)$ & $7(14)$ \\
\hline 0-60 min, $\mathrm{n}(\%)$ & $30(11)$ & $14(14)$ & $68(31)$ & $20(29)$ & $55(26)$ & $14(27)$ \\
\hline $60-120 \min , \mathrm{n}(\%)$ & $55(20)$ & $20(21)$ & $47(21)$ & $18(26)$ & $52(25)$ & $13(25)$ \\
\hline$>120 \min , \mathrm{n}(\%)$ & $191(69)^{2}$ & $60(62)^{4}$ & $60(27)^{6}$ & $24(34)^{1}$ & $56(27)^{10}$ & $18(35)$ \\
\hline \multicolumn{7}{|l|}{ Type of PA participation, n (\%) } \\
\hline Football (soccer) & $101(36)$ & $31(32)$ & $3(2)$ & $11(16)$ & $4(2)$ & $6(12)$ \\
\hline Floorball & $32(12)$ & $7(7)$ & $1(0.5)$ & $0(0)$ & $3(2)$ & $1(2)$ \\
\hline Strength training & $25(9)$ & $8(8)$ & $52(26)$ & $17(24)$ & $46(26)$ & $8(15)$ \\
\hline Running & $24(9)$ & $5(5)$ & $12(6)$ & $4(6)$ & $29(17)$ & $2(4)$ \\
\hline Handball & $17(6)$ & $3(3)$ & $0(0)$ & $0(0)$ & $0(0)$ & $0(0)$ \\
\hline Walking & $6(2)$ & $4(4)$ & $18(9)$ & $5(7)$ & $14(8)$ & $6(12)$ \\
\hline Cycling & $7(3)$ & $3(3)$ & $46(23)$ & $14(20)$ & $34(19)$ & $9(17)$ \\
\hline Other sports & $49(26)^{1}$ & $38(40)^{5}$ & $68(34)^{29}$ & $19(27)^{1}$ & $46(26)^{43}$ & $20(38)$ \\
\hline Tegner Activity Scale Median (IQR) & $7(5)^{1}$ & $7(5) 3$ & $4(2)$ & $4(3)^{*}$ & $4(2)$ & $4(3)^{*}$ \\
\hline \multicolumn{7}{|l|}{ IKDC activity level, n (\%) } \\
\hline Level I & $155(56)$ & $47(50)$ & $5(2)$ & $13(18)$ & $9(4)$ & $10(20)$ \\
\hline Level II & $40(14)$ & $18(19)$ & $12(5)$ & $6(9)$ & $8(4)$ & $9(17)$ \\
\hline Level III & $83(30)$ & $27(29)$ & $136(59)$ & $40(56)$ & $134(61)$ & $25(48)$ \\
\hline Level IV & $0(0)^{1}$ & $2(2)^{7}$ & $76(33)^{3}$ & $12(17)^{\star}$ & $68(31)$ & $8(15)^{\star}$ \\
\hline \multicolumn{7}{|l|}{ Return to preinjury PA, $\mathrm{n}(\%)$} \\
\hline Goal to return $\dagger$ & $263(95)$ & 92(99) & & & & \\
\hline Have returned yes/no (\%) & & & $20 / 181(10 / 90)^{28}$ & $24 / 46(34 / 66)^{1 *}$ & $28 / 140(17 / 83)^{51 *}$ & $21 / 30(41 / 59)$ \\
\hline \multicolumn{7}{|c|}{ Reason for not returned to preinjury PA, n (\%) } \\
\hline Completing rehabilitation & & & $112(62)$ & $26(57)$ & $70(54)$ & $9(30)$ \\
\hline Poor knee function & & & $33(18)$ & $8(17)$ & $22(17)$ & $10(33)$ \\
\hline Fear/do not trust the knee & & & $25(14)$ & $5(24)$ & $27(21)$ & $6(20)$ \\
\hline Other reason & & & $11(6)$ & $1(2)$ & $10(8)^{11}$ & $5(17)$ \\
\hline
\end{tabular}

Superscript number indicates number of participants with missing data.

*Significant different to ACL-group $(p<0.05)$.

†Including patients who had returned.

IKDC, International Knee Documentation Committee.

of our participants was to return to their preinjury activity. Return to the preinjury sport is one of the criteria for defining successful outcome after ACL injury and/or reconstruction ${ }^{30}$ and may increase patient satisfaction. ${ }^{9}$ In addition, team sports, to which most of our participants

Table 4 Surgery within 6 months following primary injury

\begin{tabular}{lcc} 
& ACL (n=279) & $\begin{array}{c}\text { Other knee injuries } \\
(\mathbf{n}=\mathbf{1 0 1})\end{array}$ \\
\hline Diagnostic arthroscopy & 3 & 1 \\
ACLR & 109 & - \\
Meniscus repair & 3 & 1 \\
Meniscus resection & 7 & 3 \\
Other & 6 & 1 \\
\hline
\end{tabular}

Main surgery is described.

ACLR, ACL reconstruction. aim to return, may give further positive effects on health, compared with individual sports. ${ }^{31}$ On the other hand, lifelong participation in physical activity may be more important. Return to high demanding sports after initial knee injury increases the risk for new knee injuries, ${ }^{32}$ that increase the risk for both knee osteoarthritis and lower physical activity levels. ${ }^{33}$ Activity modification can be central pillar of treatment after knee injuries, to reduce the risk of osteoarthritis ${ }^{34}$ and make it possible for people to have a lifelong physical activity participation reaching the recommended levels.

\section{Participation in physical activity}

The number of participants who met the recommended level of physical activity before knee injury was equal to worldwide reported levels of activity (approximately $65 \%$ ). This is approximately $10 \%$ higher that activity 


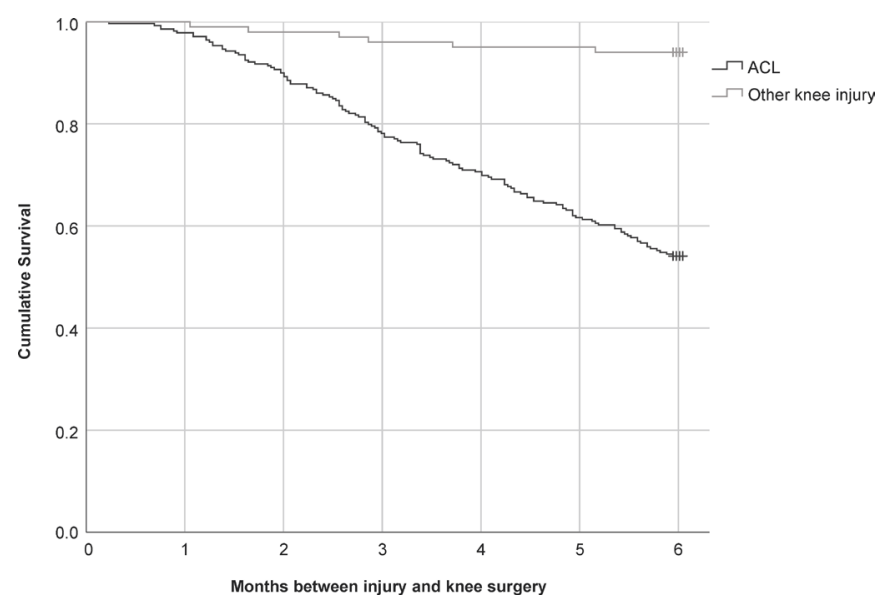

Figure 2 Kaplan-Meier curve showing time to surgery in the ACL injury group and other knee injuries group.

participation of the general Swedish population. ${ }^{35}$ Three and 6 months after the knee injury, the number who met physical activity recommendations reduced by almost $50 \%$, and only one in every three participants reached the recommended level. Most of the participants with ACL injury were still completing rehabilitation. Practicing rehabilitation exercises, especially during the middle and late phase of rehabilitation, is close to the recommended physical activity level ${ }^{36}$ (ie, $20 \mathrm{~min}$ vigorous-intensity physical activity three times per week). ${ }^{2}$ Rehabilitation after ACLR usually lasts between 9 and 12 months ${ }^{36}$ and approximately $80 \%$ return to some form of sport. ${ }^{8}$ On the other hand, only half of participants with other knee injuries were completing rehabilitation at the 3-month and/or 6-month follow-up. One in five participants who reported that they had not returned to their preinjury activity level were not completing rehabilitation, despite having as a goal to return to their preinjury sport. Low levels of physical activity after knee injury have been reported as long as 12 months after the injury, and physical activity level was not dependent on functional recovery. ${ }^{37}$ For our participants with other knee injuries, there is a risk for continuing low levels of physical activity. Clinicians might consider whether more active input is required to facilitate full recovery and return to desired and high physical activity levels. ${ }^{31}$

\section{Subgroups of knee injuries}

In the present study, we report all other knee injuries as one group. There were too few participants for subgroup analyses, and descriptive results for each diagnosis can be found in online supplemental file. The results indicate worse outcome after patella dislocation and cartilage injuries compared with other minor injuries. Previous studies have shown that patients with posterior cruciate ligament injury ${ }^{10}{ }^{11}$ and meniscus injury ${ }^{12}$ could make a return to preinjury physical activity $2-6$ months after the injury, depending on type of treatment. On the other hand, after a patellar dislocation, only two out of three returned to preinjury level of physical activity at all, with or without surgery. ${ }^{13}$ Our results for specific injury diagnoses support previous work.

When interpreting our results from participants with ACL injury, one must consider that $39 \%$ of the participants had ACLR within the follow-up period. The decision for ACLR within 3 months from injury was mainly taken due to participants high activity demands. The reasons for deciding on ACLR after 3 months was both knee joint instability and high activity demands. ${ }^{38}$ Self-reported function and activity participation may have been influenced by the surgery. Most participants with ACL injury also reported that they were completing rehabilitation. The incidence of other knee surgeries was similar in the two groups ( 7 resp 6\%).

\section{Limitations}

Only one of the clinics included participants with other acute knee injuries. The grouping of the participants in ACL versus non-ACL injury may introduce a bias. Though, other characteristics like number of knee surgeries, excluding ACLR, and demographics were similar between the groups. Due to the study design, ${ }^{18}$ there were some missing IKDC-SKF data from participants who had ACLR. Only half of the participants with other knee injuries responded to the 6 months questionnaire, and we were unable to conduct subgroup analyses for different injury types. Still, this is one of few studies reporting that both function and activity participation is affected after different types of knee injuries.

\section{CONCLUSION}

Acute knee injuries, including ACL injuries, affect selfreported knee function and physical activity participation at a minimum 6 months after index injury. More research is needed for patients with different kinds of acute knee injuries to help them return to their preinjury physical activity, and achieve satisfaction with their knee function.

Twitter Joanna Kvist @JoannaKvist

Acknowledgements The authors would like to thank the participants for their valuable contribution to the study. We would also like to thank $\mathrm{Dr}$ Clare Ardern for language revision and Henrik Hedevik at Linköping University for statistical support. This study is a part of the NACOX-cohort, a project investigating the natural corollaries and recovery after acute ACL injury.

Contributors JK and HG, together with the NACOX-study group, planned the study. SF and JK performed the analyses. All authors interpreted the data. SF drafted the manuscript, that was critically revised by all authors. All authors read and approved of the final manuscript. JK is the study guarantor.

Funding The NACOX-cohort study is supported by the Swedish Medical Research Council (VR 2015-03687 and VR 2018-02563), Swedish Research Council for Sport Science (CIF P2017-0151, P2018-0132 and P2019-0071), ALF Grants Region Östergötland (LIO-798907, LIO-900721) and the Medical Research Council of Southeast Sweden (FORSS-856741).

Competing interests None declared.

Patient consent for publication Not required.

Ethics approval The study was approved by Swedish Ethical Review Authority: 2016/44-31.

Provenance and peer review Not commissioned; externally peer reviewed.

Data availability statement Deidentified data are available from the authors upon reasonable request. 
Open access This is an open access article distributed in accordance with the Creative Commons Attribution Non Commercial (CC BY-NC 4.0) license, which permits others to distribute, remix, adapt, build upon this work non-commercially, and license their derivative works on different terms, provided the original work is properly cited, appropriate credit is given, any changes made indicated, and the use is non-commercial. See: http://creativecommons.org/licenses/by-nc/4.0/.

ORCID iD

Joanna Kvist http://orcid.org/0000-0003-3527-5488

\section{REFERENCES}

1 Ferry T, Bergström U, Hedström EM, et al. Epidemiology of acute knee injuries seen at the Emergency Department at Umeå University Hospital, Sweden, during 15 years. Knee Surg Sports Traumatol Arthrosc 2014;22:1149-55.

2 WHO. Global recommendations on physical activity for health. Geneva: World Health Organization, 2010.

3 Aman M, Forssblad M, Henriksson-Larsén K. Insurance claims data: a possible solution for a national sports injury surveillance system? an evaluation of data information against ASIDD and consensus statements on sports injury surveillance. BMJ Open 2014;4:e005056.

4 Hägglund M, Waldén M. Risk factors for acute knee injury in female youth football. Knee Surg Sports Traumatol Arthrosc 2016;24:737-46.

5 McGuine TA, Winterstein A, Carr K, et al. Changes in self-reported knee function and health-related quality of life after knee injury in female athletes. Clin J Sport Med 2012;22:334-40.

6 Lam KC, Thomas SS, Valier ARS, et al. Previous knee injury and health-related quality of life in collegiate athletes. $J$ Athl Train 2017;52:534-40

7 Filbay SR, Ackerman IN, Russell TG, et al. Return to sport matterslonger-term quality of life after ACL reconstruction in people with knee difficulties. Scand J Med Sci Sports 2017;27:514-24.

8 Ardern CL, Taylor NF, Feller JA, et al. Fifty-five per cent return to competitive sport following anterior cruciate ligament reconstruction surgery: an updated systematic review and meta-analysis including aspects of physical functioning and contextual factors. $\mathrm{Br} J$ Sports Med 2014;48:1543-52.

9 Ardern CL, Österberg A, Sonesson S, et al. Satisfaction with knee function after primary anterior cruciate ligament reconstruction is associated with self-efficacy, quality of life, and returning to the Preinjury physical activity. Arthroscopy 2016;32:1631-8.

10 Agolley D, Gabr A, Benjamin-Laing H, et al. Successful return to sports in athletes following non-operative management of acute isolated posterior cruciate ligament injuries: medium-term follow-up. Bone Joint J 2017;99-B:774-8.

11 Shelbourne KD, Muthukaruppan Y. Subjective results of nonoperatively treated, acute, isolated posterior cruciate ligament injuries. Arthroscopy 2005;21:457-61.

12 Brelin AM, Rue J-PH. Return to play following meniscus surgery. Clin Sports Med 2016;35:669-78.

13 Ménétrey J, Putman S, Gard S. Return to sport after Patellar dislocation or following surgery for patellofemoral instability. Knee Surg Sports Traumatol Arthrosc 2014;22:2320-6.

14 Regalado G, Lintula H, Kokki H, et al. Six-year outcome after non-surgical versus surgical treatment of acute primary Patellar dislocation in adolescents: a prospective randomized trial. Knee Surg Sports Traumatol Arthrosc 2016;24:6-11.

15 Malm C, Jakobsson J, Isaksson A. Physical activity and sportsreal health benefits: a review with insight into the public health of Sweden. Sports 2019;7. doi:10.3390/sports7050127. [Epub ahead of print: 23 May 2019].

16 Andersen MH, Ottesen L, Thing LF. The social and psychological health outcomes of team sport participation in adults: an integrative review of research. Scand J Public Health 2019;47:832-50.

17 Øiestad BE, Engebretsen L, Storheim K, et al. Knee osteoarthritis after anterior cruciate ligament injury: a systematic review. Am J Sports Med 2009;37:1434-43.
18 Kvist J, Gauffin H, Tigerstrand Grevnerts H, et al. Natural corollaries and recovery after acute ACL injury: the NACOX cohort study protocol. BMJ Open 2018;8:e020543.

19 Winterstein AP, McGuine TA, Carr KE, et al. Comparison of IKDC and SANE outcome measures following knee injury in active female patients. Sports Health 2013;5:523-9.

20 Tigerstrand Grevnerts H, Grävare Silbernagel K, Sonesson S, et al. Translation and testing of measurement properties of the Swedish version of the IKDC subjective knee form. Scand J Med Sci Sports 2017;27:554-62.

21 Grevnerts HT, Terwee CB, Kvist J. The measurement properties of the IKDC-subjective knee form. Knee Surg Sports Traumatol Arthrosc 2015;23:3698-706.

22 Muller B, Yabroudi MA, Lynch A, et al. Defining thresholds for the patient acceptable symptom state for the IKDC subjective knee form and KOOS for patients who underwent ACL reconstruction. Am J Sports Med 2016;44:2820-6.

23 Garcia AN, Cook C, Lutz A, et al. Concurrent validity of the single assessment numerical evaluation and patient-reported functional measures in patients with musculoskeletal disorders: an observational study. Musculoskelet Sci Pract 2019;44:102057.

24 Olsson SJG, Ekblom Örjan, Andersson E, et al. Categorical answer modes provide superior validity to open answers when asking for level of physical activity: a cross-sectional study. Scand J Public Health 2016;44:70-6.

25 Tegner Y, Lysholm J. Rating systems in the evaluation of knee ligament injuries. Clin Orthop Relat Res 1985;198:42???49-9.

26 Hefti F, Müller W, Jakob RP, et al. Evaluation of knee ligament injuries with the IKDC form. Knee Surg Sports Traumatol Arthrosc 1993;1:226-34.

27 Grindem H, Eitzen I, Snyder-Mackler L, et al. Online registration of monthly sports participation after anterior cruciate ligament injury: a reliability and validity study. Br J Sports Med 2014;48:748-53.

28 Straume-Næsheim TM, Randsborg P-H, Mikaelsen JR, et al. Recurrent lateral patella dislocation affects knee function as much as ACL deficiency - however patients wait five times longer for treatment. BMC Musculoskelet Disord 2019;20:318

29 Grevnerts HT, Fältström A, Sonesson S, et al. Activity demands and instability are the most important factors for recommending to treat ACL injuries with reconstruction. Knee Surg Sports Traumatol Arthrosc 2018;26:2401-9.

30 Lynch AD, Logerstedt DS, Grindem $\mathrm{H}$, et al. Consensus criteria for defining 'successful outcome' after ACL injury and reconstruction: a Delaware-Oslo ACL cohort investigation. Br J Sports Med 2015;49:335-42.

31 Mountjoy M, Junge A. The role of international sport Federations in the protection of the athlete's health and promotion of sport for health of the general population. Br J Sports Med 2013;47:1023-7.

32 Fältström A, Kvist J, Gauffin H, et al. Female soccer players with anterior cruciate ligament reconstruction have a higher risk of new knee injuries and quit soccer to a higher degree than Knee-Healthy controls. Am J Sports Med 2019;47:31-40.

33 Fältström $A$, Hägglund $M$, Kvist J. Patient-reported knee function, quality of life, and activity level after bilateral anterior cruciate ligament injuries. Am J Sports Med 2013;41:2805-13.

34 Kostogiannis I, Ageberg E, Neuman P, et al. Activity level and subjective knee function 15 years after anterior cruciate ligament injury: a prospective, longitudinal study of nonreconstructed patients. Am J Sports Med 2007;35:1135-43.

35 Hallal PC, Andersen LB, Bull FC, et al. Global physical activity levels: surveillance progress, pitfalls, and prospects. Lancet 2012;380:247-57.

36 van Melick N, van Cingel REH, Brooijmans F, et al. Evidencebased clinical practice update: practice guidelines for anterior cruciate ligament rehabilitation based on a systematic review and multidisciplinary consensus. Br J Sports Med 2016;50:1506-15.

37 Andrew N, Wolfe R, Cameron P, et al. The impact of sport and active recreation injuries on physical activity levels at 12 months postinjury. Scand J Med Sci Sports 2014;24:377-85.

38 Tigerstrand Grevnerts $\mathrm{H}$. Treatment decision after anterior cruciate ligament injury, and evaluation of measurement properties of a patient reported outcome measure. Linköping University, 2019. 